\title{
In-situ early-age hydration study of sulfobelite cements by synchrotron powder diffraction
}

\author{
G. Álvarez-Pinazo a, A. Cuesta a , M. García-Maté a , I. Santacruz ${ }^{\text {a }}$, E.R. Losilla ${ }^{\text {a }}$, S.G. Sanfélix ${ }^{\text {b }}$, F. Fauth ${ }^{\text {c }}$, \\ M.A.G. Aranda ${ }^{\mathrm{a}, \mathrm{c}}$, A.G. De la Torre ${ }^{\mathrm{a}, *}$
}

a Departamento de Química Inorgánica, Universidad de Málaga, Campus Teatinos S/N., 29071 Málaga, Spain

b Unidad Técnica de Investigación de Materiales, AIDICO, Avda. Benjamín Franklin, 17 Paterna, Valencia, Spain

c CELLS-Alba synchrotron, Carretera BP 1413, Km. 3.3, E-08290 Cerdanyola, Barcelona, Spain

\section{A R T I C L E I N F O}

\section{Article history:}

Received 11 July 2013

Accepted 24 October 2013

Available online $\mathrm{xxxx}$

\section{Keywords:}

Hydration (A)

X-ray diffraction (B)

Kinetics (A)

Sulfoaluminate (D)

$\mathrm{Ca}_{2} \mathrm{SiO}_{4}(\mathrm{D})$

\begin{abstract}
A B S T R A C T
Eco-friendly belite calcium sulfoaluminate (BCSA) cement hydration behavior is not yet well understood. Here, we report an in-situ synchrotron X-ray powder diffraction study for the first hours of hydration of BCSA cements. Rietveld quantitative phase analysis has been used to establish the degree of reaction $(\alpha)$. The hydration of a mixture of ye'elimite and gypsum revealed that ettringite formation ( $\alpha \sim 70 \%$ at $50 \mathrm{~h}$ ) is limited by ye'elimite dissolution. Two laboratory-prepared BCSA cements were also studied: non-active-BCSA and active-BCSA cements, with $\beta$ - and $\alpha^{\prime}{ }_{\mathrm{H}}$-belite as main phases, respectively. Ye'elimite, in the non-active-BCSA system, dissolves at higher pace $(\alpha \sim 25 \%$ at $1 \mathrm{~h})$ than in the active-BCSA one $(\alpha \sim 10 \%$ at $1 \mathrm{~h})$, with differences in the crystallization of ettringite ( $\alpha \sim 30 \%$ and $\alpha \sim 5 \%$, respectively). This behavior has strongly affected subsequent belite and ferrite reactivities, yielding stratlingite and other layered phases in non-active-BCSA. The dissolution and crystallization processes are reported and discussed in detail.
\end{abstract}

(c) 2013 Elsevier Ltd. All rights reserved.

\section{Introduction}

Concrete is the most used artificial material, $6 \mathrm{~km}^{3} /$ year or more than 2.5 tones per person yearly. This is due to many interesting features including low price, high versatility, remarkable change in mechanical properties during setting and chemical durability. The hydration of cements, to yield concrete, is a very complex process in which some crystalline phases are dissolved in free water. Pore solution becomes saturated in some ions, and after oversaturation, some crystalline and amorphous hydrated phases start to precipitate [1,2]. These processes are responsible for the development of a given microstructure (type, amount and distribution of the constituent phases, usually with chemical substitutions on the crystalline phases, and porous distribution) which is the fundamental link between chemical processes and final properties/performances. Many factors may affect the equilibrium between hydrous phases, pore solution, gel/amorphous phases and clinker phases, and their kinetics of dissolution and formation. Because of that, it is essential to understand (and at later stage to control) the hydration processes, in particular within the first few hours of hydration, named in the field as early hydration [2].

However, the complexity and heterogeneity of cementitious materials make difficult the understanding of the process-microstructureproperties relationship. Furthermore, there are only a few rapid, reliable and accurate techniques to quantify the amounts of the different phases

\footnotetext{
* Corresponding author. Tel.: + 34 952131877; fax: + 34952132000.

E-mail address: mgd@uma.es (A.G. De la Torre).
}

present in the hydrated cements (pastes), including amorphous contents and porous (micro) structure [3-6]. Due to these difficulties, the details of the hydration process of cements are still not completely clarified, even when the cement chemistry is well known in its most important features, as it is the case for ordinary Portland cement (OPC) [2]. These problems are enhanced for novel cementitious materials. Scientific community is searching for new cements with improved performances, such as high strengths and good workability of their corresponding concretes and/or environmentally friendly binders [7]. However, prior to the reliable use of any new binder, the hydration chemistry and durability of the mortars and concretes must be profoundly studied and characterized, as the safety and wealth of people are very much related to building industry.

Belite calcium sulfoaluminate [8], BCSA or sulfobelite, cements are considered environmentally friendly building materials, as their production may have up to $35 \%$ lower $\mathrm{CO}_{2}$ footprint than OPC fabrication. They are prepared by mixing the clinker with different amounts of a calcium sulfate set regulator such as gypsum, bassanite or anhydrite. Hereafter cement nomenclature will be used: $\mathrm{C}=\mathrm{CaO}, \mathrm{S}=\mathrm{SiO}_{2}$, $\mathrm{A}=\mathrm{Al}_{2} \mathrm{O}_{3}, \mathrm{~F}=\mathrm{Fe}_{2} \mathrm{O}_{3}, \underline{\mathrm{S}}=\mathrm{SO}_{3}, \mathrm{~T}=\mathrm{TiO}_{2}$ and $\mathrm{H}=\mathrm{H}_{2} \mathrm{O}$. BCSA cements are based on belite $\left(\mathrm{C}_{2} \mathrm{~S}\right)$, ye'elimite (also called Klein's salt or tetracalcium trialuminate sulfate $\left.\left(\mathrm{C}_{4} \mathrm{~A}_{3} \mathrm{~S}\right)\right)$ and other minor phases, such as ferrite $\left(C_{4} A F\right)[9-13]$ or calcium aluminates $\left(C_{12} A_{7}\right)[14]$ and calcium sulfate $\left(\mathrm{CSH}_{\mathrm{X}}\right)$ as set retarder. The hydration of BCSA cements strongly depends on the amount and reactivity of the added calcium sulfate [15] and the presence of minor phases. Most of the hydration heat is released within the first $12-24 \mathrm{~h}$ of hydration [11,16,17]. The 
water demand needed for a complete hydration process is determined by the amount of calcium sulfate and silicates. The required water/ cement ratio is slightly higher than that for OPC (for complete hydration). The dispersion of agglomerated cement particles in water is a key point to improve the workability of concrete to obtain more homogeneous mixtures and to reduce the amount of mixing water [18]. During early age hydration, i.e. up to 3 days, ettringite or $A F t\left(C_{6} A_{3} \mathrm{H}_{32}\right)$ phase is the main crystalline hydration product formed in BCSA cements from the dissolution of ye'elimite and calcium sulfate(s). This process can be expressed by the following chemical reaction:

$\mathrm{C}_{4} \mathrm{~A}_{3} \underline{\mathrm{S}}+2 \mathrm{CS}_{\mathrm{x}}+(38-2 \mathrm{x}) \mathrm{H} \rightarrow \mathrm{C}_{6} \mathrm{AS}_{3} \mathrm{H}_{32}+2 \mathrm{AH}_{3}$.

In addition, dicalcium silicate is the main anhydrous phase in BCSA. The hydration kinetic of $C_{2} S$ is slow when compared to $C_{3} S$, which is the main phase in OPC. Some efforts are being performed to enhance BCSA hydration kinetic, for instance, by adding minor elements (f.i. sodium and boron as borax) during clinkering to obtain high temperature polymorphs of belite, i.e. $\alpha$-forms [12,13,19]. Independently of the kinetic of the reaction, $\mathrm{C}_{2} \mathrm{~S}$ may yield stratlingite $[16,19]\left(\mathrm{C}_{2} \mathrm{ASH}_{8}\right)$ or amorphous $\mathrm{CSH}$-gel and portlandite $(\mathrm{CH})$. Moreover, belite would dissolve to form stratlingite only in the case of high available amounts of aluminum hydroxide. These two alternative chemical processes can be expressed as the following reactions:

$\mathrm{C}_{2} \mathrm{~S}+\mathrm{AH}_{3}+5 \mathrm{H} \rightarrow \mathrm{C}_{2} \mathrm{ASH}_{8}$

$\mathrm{C}_{2} \mathrm{~S}+(2-\mathrm{y}+\mathrm{x}) \mathrm{H} \rightarrow \mathrm{C}_{\mathrm{y}} \mathrm{SH}_{\mathrm{x}}+(2-\mathrm{y}) \mathrm{CH}$.

Minor phases present in the anhydrous cement may provoke the precipitation of other hydration products such as monosulfoaluminate $\left(\mathrm{C}_{4} \mathrm{ASH}_{8}+\mathrm{x}\right)$ and hydrogarnet phases such as katoite $\left(\mathrm{C}_{3} \mathrm{AS}_{3}-{ }_{\mathrm{x}} \mathrm{H}_{2 \mathrm{x}}\right.$ with $1.5<\mathrm{x}<3$ ) $[1,11,13,19-21]$. The reactivity of ferrite $\left(C_{4} A F\right)$ during hydration in these cements is slower than that of $\mathrm{C}_{4} \mathrm{~A}_{3} \mathrm{~S}$ [22] and it is not well understood.

X-ray powder diffraction (XRPD) is a powerful tool for material characterization in general, and for in-situ studies of chemical processes in particular $[4,5,23]$. During the last years, several authors have described the quantitative phase analysis of cements, clinkers and supplementary cementitious materials by combining XRPD and Rietveld methodology [24-28], establishing sources of errors and dependence on the results of Rietveld strategies. More recently, this has been expanded to hydrated cementitious systems [3-5,13] and in some of them, the non diffracting fraction, also named as Amorphous and Crystalline notquantified, ACn [29], was also calculated [30,31]. Furthermore, the use of an intense X-ray source, such as synchrotron X-rays, coupled with a fast X-ray detector permits time-resolved diffraction experiments allowing in-situ measurements during the hydration process of cements $[4,5,13,14,32,33]$.

In this work we report the in-situ hydration study of two iron-rich sulfobelite cements [28] and a model mixture of ye'elimite and gypsum through synchrotron XRPD (SXRPD) and Rietveld methodology. Kinetics of hydration and factors influencing the hydration reactions have been established and correlated to calorimetric data.

\section{Experimental section}

\subsection{Sample preparation}

Commercial micronized natural gypsum, $\mathrm{CSH}_{2}$, marketed by BELITH S.P.R.L. (Belgium) was used to prepare cements [18]. Bassanite, $\mathrm{CSH}_{0.5}$, and anhydrite, CS, were synthesized by heating gypsum at $90{ }^{\circ} \mathrm{C}$ for $24 \mathrm{~h}$ in a stove and at $700{ }^{\circ} \mathrm{C}$ for $1 \mathrm{~h}$ in a furnace, respectively.

Stoichiometric ye'elimite $\left(\mathrm{C}_{4} \mathrm{~A}_{3} \mathrm{~S}\right)$, prepared as previously reported [34], was mixed with gypsum according to the stoichiometry of reaction (1). The resulting mixture is hereafter labeled as $\mathrm{G}_{-} \mathrm{C}_{4} \mathrm{~A}_{3} \mathrm{~S}$. Two
BCSA clinkers, B0 and B2, were used and their preparation procedures have been already reported [28]. B0 stands for a laboratory-prepared BCSA clinker without any activation and B2 for an activated one by adding borax ( $2 \mathrm{wt} . \%$ as $\mathrm{B}_{2} \mathrm{O}_{3}$ ). These clinkers were mixed with 10 wt.\% of gypsum (G), bassanite (B) or anhydrite (A) in order to obtain different cements, hereafter $\mathrm{G} 10 \mathrm{Bx}, \mathrm{B} 10 \mathrm{Bx}$ and $\mathrm{A} 10 \mathrm{Bx}$, respectively; where $\mathrm{x}$ can be either 0 or 2 . Blaine parameters were $4800 \mathrm{~cm}^{2} / \mathrm{g}$ for G- $\mathrm{C}_{4} \mathrm{~A}_{3} \mathrm{~S}$, close to $4000 \mathrm{~cm}^{2} / \mathrm{g}$ for G10Bx cements and to $3000 \mathrm{~cm}^{2} / \mathrm{g}$ for $\mathrm{B} 10 \mathrm{Bx}$ and $\mathrm{A} 10 \mathrm{Bx}$ cements. Cement pastes were prepared ex-situ by mixing cement with water at $\mathrm{w} / \mathrm{c}=0.55$ (mass ratio) and $\mathrm{G}-\mathrm{C}_{4} \mathrm{~A}_{3} \mathrm{~S}$ was mixed using $\mathrm{w} / \mathrm{c}=0.71$. Finally, pastes were immediately introduced into glass capillaries of $0.5 \mathrm{~mm}$ of diameter with a syringe. The capillaries were sealed with wax and grease to avoid any water loss.

\subsection{SXRPD data acquisition and analysis}

SXRPD patterns were collected in Debye-Scherrer (transmission) mode using the X-ray powder diffraction station of ALBA, the Spanish Synchrotron Radiation Facility (Barcelona, Spain) [35]. The wavelength, 0.61984(3) Å, was selected with a double-crystal Si (111) monochromator and determined from a Si640d NIST standard ( $a=5.43123 \AA$ ) measurement. The diffractometer is equipped with a so called MYTHEN detector system especially suited for time-resolved experiments. The capillaries were rotated during data collection to improve diffracting particle statistics. The data acquisition time was $\sim 15$ min per pattern to attain very good signal-to-noise ratio over the angular range $1-35^{\circ}$ (20). The temperature inside the experimental hutch was $26(1){ }^{\circ} \mathrm{C}$.

Raw SXRPD patterns were normalized taking into account the loss of $\mathrm{X}$-ray beam flux with time due to the electron beam current decline in the storage ring. Normalized SXRPD patterns were analyzed by using the Rietveld methodology as implemented in the GSAS software package [36], in order to obtain Rietveld Quantitative Phase Analysis (RQPA). Crystal structure descriptions used for all the phases were those included in references $[28,29]$. However, a revised crystallographic description was used for $\mathrm{C}_{4} \mathrm{~A}_{3} \mathrm{~S}$ [34]. Final global optimized parameters were: 20 shifted chebyshev background coefficients, zero-shift error, cell parameters and peak shape parameters. Peak shapes were fitted by using the pseudo-Voigt function [37]. The WinPLOTR program suite [38] was used to extract the full width at half maximum (FWHM) of selected individual peaks.

\subsection{Setting time}

Paste setting times were determined using the Vicat test method according to UNE-EN 196-3.

\section{4. $p H$ measurement}

A fraction of the as prepared $\mathrm{G} 10 \mathrm{~B} 0$ and $\mathrm{G} 10 \mathrm{~B} 2$ pastes was filtered in a Whatman filter (pore size of $8 \mu \mathrm{m}$ ) after $10 \mathrm{~min}$ of hydration. The $\mathrm{pH}$ of the filtration waters was measured by using standard digital $\mathrm{pH}$ meter.

\subsection{Calorimetries}

The isothermal calorimetric study was performed for all samples in an eight channel Thermal Activity Monitor (TAM) instrument using glass ampoules. Pastes were prepared by mixing $\sim 6 \mathrm{~g}$ of each sample with the appropriated water ( $\mathrm{w} / \mathrm{c}$ ratio of 0.55 for cements and $\mathrm{w} / \mathrm{c}=0.71$ for ye'elimite-gypsum mixture) and the heat flow was collected up to 168 h at $20^{\circ} \mathrm{C}$.

\subsection{Scanning Electron Microscopy (SEM)}

Anhydrous clinker pellets were observed in a JEOL JSM-6490LV scanning electron microscope. The samples were previously polished 
down to $1 \mu \mathrm{m}$ using diamond spray and further sputtered with Au or graphite. EDX measurements were carried out (on samples coated with graphite) with the OXFORD INCA Energy 350 attachment. This unit has a $\mathrm{Si}(\mathrm{Li})$ detector with a super atmospheric thin window (SATW).

\section{Results and discussions}

\subsection{Hydration of stoichiometric ye'elimite and gypsum}

The dissolution of ye'elimite and gypsum starts right after the addition of water. Table A1, given as supporting information, reports direct RQPA for $\mathrm{G}_{-} \mathrm{C}_{4} \mathrm{~A}_{3} \mathrm{~S}$ as a function of hydration time up to $58 \mathrm{~h}$. The overall reactivity of this sample should follow Eq. (1), although as mentioned in the Introduction section, cement phase reactivity is governed by dissolution/saturation/crystallization processes. Thus, gypsum and ye'elimite both should start to dissolve, so crystalline AFt and aluminate hydrate phase should precipitate. We have quantified very small amounts of crystalline $\mathrm{AH}_{3}$, in the form of gibbsite. Most of the aluminate hydrate is ill-crystallized in agreement with previous observations [17,19,39].

It has to be borne in mind that at the very beginning, i.e. time $=0$, the mix is composed by crystalline gypsum, crystalline ye'elimite and free water; only the two former phases can be quantified by RQPA. As hydration process takes place, these two phases dissolve (diminish); and free water also diminishes to be chemically bounded to hydrate phases, i.e. AFt and $\mathrm{AH}_{3}$ (both crystalline and amorphous). The fact that the whole crystalline fraction of the sample is changing with time represents an inherent difficulty for the interpretation of direct RQPA results. Since $\mathrm{G}-\mathrm{C}_{4} \mathrm{~A}_{3} \mathrm{~S}$ is a simple system, we have been able to estimate the degree of reaction of each phase by comparing theoretical data with experimental data, the latter included in Table A1.

The theoretical data were calculated taking into account that the sample was prepared in a stoichiometric ratio according to Eq. (1); thus the composition of the mixture at $0.0 \mathrm{~h}$ of hydration is: $38.9 \mathrm{wt} . \%$ of ye'elimite, $22.0 \mathrm{wt} . \%$ of gypsum and $39.1 \mathrm{wt} . \%$ of free water. Taking into account these values, we can calculate the theoretical amount of phases dissolved and formed, assuming that the reaction degree of independent phases is the same. As an example, a reaction degree $(\alpha)$ of $10 \%$ for both ye'elimite and gypsum will be now considered. Then according to Eq. (1), that sample should contain $35.1 \mathrm{wt} . \%$ of ye'elimite, $19.8 \mathrm{wt} . \%$ of gypsum, $8.0 \mathrm{wt} . \%$ of AFt, $2.0 \mathrm{wt} . \%$ of $\mathrm{AH}_{3}$ and $35.1 \mathrm{wt}$.\% of free water. These values are normalized to obtain the crystalline fraction at a reaction degree of $\alpha \sim 10 \%$, using only those percentages corresponding to crystalline phases, i.e. ye'elimite, gypsum and AFt (55.7, 31.5 and $12.8 \mathrm{wt} . \%$, respectively). These latter data are now comparable to direct Rietveld results, without taking into account gibbsite. Thus, theoretical data were tabulated for all possible $\alpha$ values. Comparing these theoretical results with data reported in Table A1, we can conclude that, at $1 \mathrm{~h}$ of hydration, ye'elimite and gypsum were dissolved at $\alpha \sim 10 \%$ and the crystallization of ettringite was slightly lower than $10 \%$. These results ( $\alpha$ vs. time) are plotted in Fig. 1a. From this figure, it can be observed that gypsum dissolution rate is (slightly) faster than that of ye'elimite within the first $10 \mathrm{~h}$ of reaction. After $10 \mathrm{~h}$, ye'elimite dissolution (and ettringite crystallization) rate increases meanwhile gypsum dissolution rate is comparatively lower.

The crystallization of AFt seems to occur jointly with the dissolution of ye'elimite. Thus, it can be inferred that ye'elimite dissolution is limiting ettringite precipitation. Nevertheless, from 23 to 58 h the sample hydration seems to be stopped as the reaction is not progressing, i.e. no dissolution and no precipitation occur. This phenomenon may be a kind of passivation, due to the precipitation of crystals of AFt surrounding $\mathrm{C}_{4} \mathrm{~A}_{3} \mathrm{~S}$ and gypsum particles, in such a way that free water is not available. We can rule out the possibility of a free water loss as the capillaries were well sealed. In addition, Fig. 1b shows direct Rietveld results and calorimetric data. The calorimetric

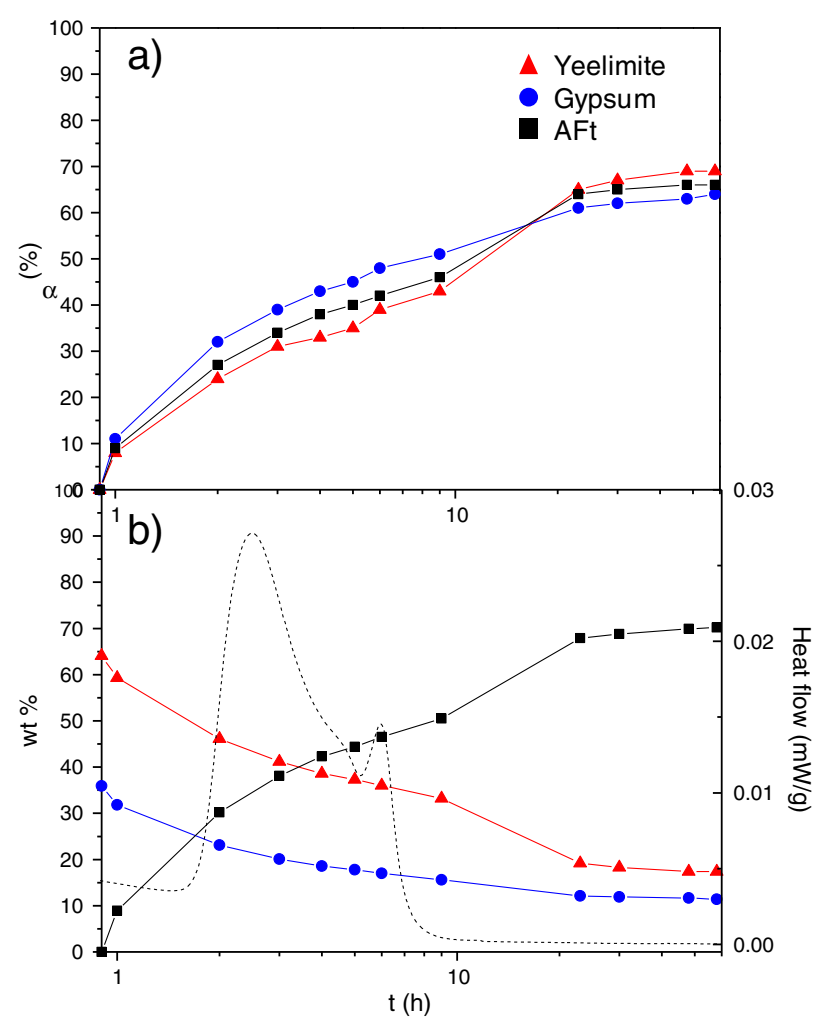

Fig. 1. Time evolution for $G-C_{4} A_{3} S$ hydration of (a) degree of reaction $[\alpha]$ of each phase during hydration and (b) direct RQPA results and the calorimetric heat flow curve (dashed line). Solid lines are just guide to the eyes.

curve shows two broad signals mainly associated to first dissolution and precipitation processes.

\subsection{Hydration of BCSA cements}

G10B0 contains $\beta-C_{2} S$ as main phase, meanwhile $\alpha^{\prime}{ }_{H^{-}} C_{2} S$ is stabilized in G10B2 due to the addition of borax to the raw mixture. These samples were studied in order to understand the influence of activation in the hydration behavior at very early ages.

Tables A2 and A3 give direct RQPA results with hydration for G10B0 and G10B2, respectively. Figs. 2 and 3 give SXRPD raw patterns of G10B0 and G10B2, respectively, at selected times of hydration.

The first important difference in the hydration process is the dissolution kinetic of gypsum and ye'elimite, as previously reported [19]. In G10B0, gypsum is completely dissolved after $5 \mathrm{~h}$ of hydration, see Fig. 2. However, in G10B2, gypsum is dissolved after 11 h, see Fig. 3. The rate of dissolution of ye'elimite is also different in both samples. Ye'elimite is fully dissolved after $26 \mathrm{~h}$ in G10B0 (see Fig. 2 and Table A2), but it is still present after $51 \mathrm{~h}$ of hydration for G10B2 (see Fig. 3 and Table A3). Moreover, the crystallization rate of AFt phase is also different in both cements. At $1 \mathrm{~h}$ of hydration G10B0 contains 14.2 (2) wt\% of AFt while at the same hydration time, only 1.9(1) wt\% was quantified for G10B2.

The $\mathrm{pH}$ value of the pastes was measured to understand the difference in dissolution rates of ye'elimite and gypsum between both systems, giving a value of $\sim 12.4$ for G10B0 and $~ 10.3$ for G10B2 (after 10 min hydration). It is known that the depletion of dissolved sulfate ions causes the increase of hydroxide concentration, and consequently a higher $\mathrm{pH}$ value [16]. The fast sulfate consumption by crystalline ettringite precipitation in $\mathrm{G} 10 \mathrm{~B} 0$ paste is responsible to the higher measured $\mathrm{pH}$ value. Furthermore, both clinkers present slightly different ye'elimite crystal structures; the non-active clinker, B0, was quantified by using a revised orthorhombic crystal structure [34], while ye'elimite 


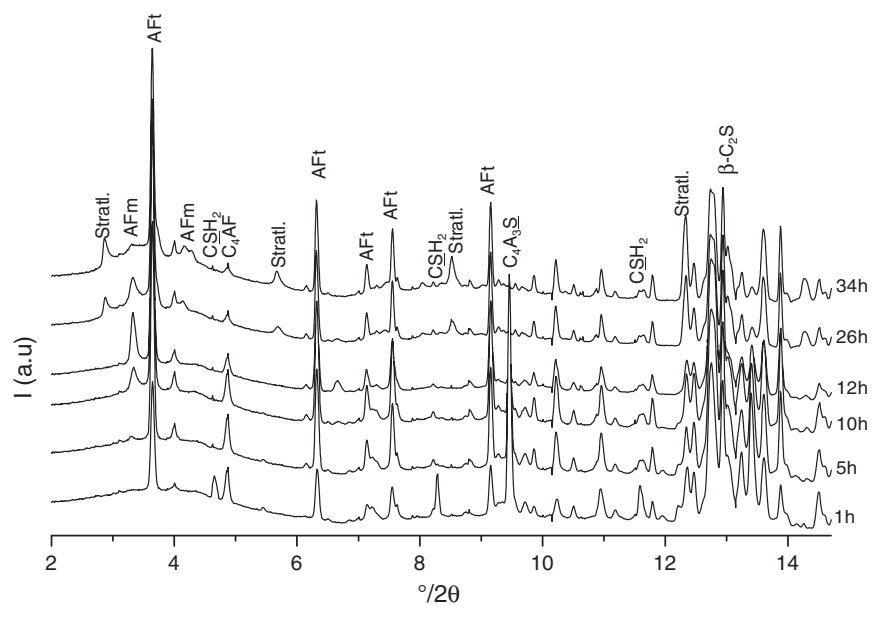

Fig. 2. Selected range of the SXRPD raw patterns for G10B0 recorded at different ages of hydration, with the main peaks due to a given phase labeled.

in B2 presents higher symmetry, thus a cubic structure was used [40]. This different crystal structures may also justify the hydrating behaviors, although more research is needed. A SEM study was performed on B0 and B2 clinkers to inspect particle morphologies and sizes. Fig. 4 shows SEM micrographs for both B0 and B2 anhydrous clinkers at different magnifications. Fig. $4 \mathrm{a}$ and $\mathrm{c}$ shows the angular shaped particles of ye'elimite, as previously described [41]. The identification of these particles was confirmed by EDX analysis, showing average $\mathrm{Al} / \mathrm{Ca}=$ 1.4 and $\mathrm{S} / \mathrm{Ca}=0.10$ ratios, which are relatively close to the theoretical values, 1.5 and 0.25 , respectively. Moreover, this study revealed that ye'elimite average particle size in B0 was slightly smaller than that in B2, arrows in Fig. 4a and c. This observation may also partly justify the faster dissolution of ye'elimite for G10B0.

The second most important difference between the hydration behaviors of these two cements takes place after $24 \mathrm{~h}$ of hydration. On the one hand, the dissolution of $\beta-C_{2} S$ and $C_{4} A F$ in G10B0 starts after one day of hydration, with the consequent crystallization of layered AFm type phases, such as stratlingite (labeled as Stratl in Fig. 2). On the other hand, for G10B2, $\alpha^{\prime}{ }_{\mathrm{H}}^{-} \mathrm{C}_{2} \mathrm{~S}$ percentage remains constant up to $51 \mathrm{~h}$ of hydration and the dissolution of $\mathrm{C}_{4} \mathrm{AF}$ is very slow after $14 \mathrm{~h}$. Fig. 5 shows Rietveld plots for (a) G10B0 at $26 \mathrm{~h}$ of hydration and (b) G10B2 at 24 h of hydration, as representative examples. The difference in reactivity of both belite polymorphs is astonishing, i.e. $\beta-\mathrm{C}_{2} \mathrm{~S}$ reacts faster than $\alpha^{\prime}{ }^{-} \mathrm{C}_{2} \mathrm{~S}$.

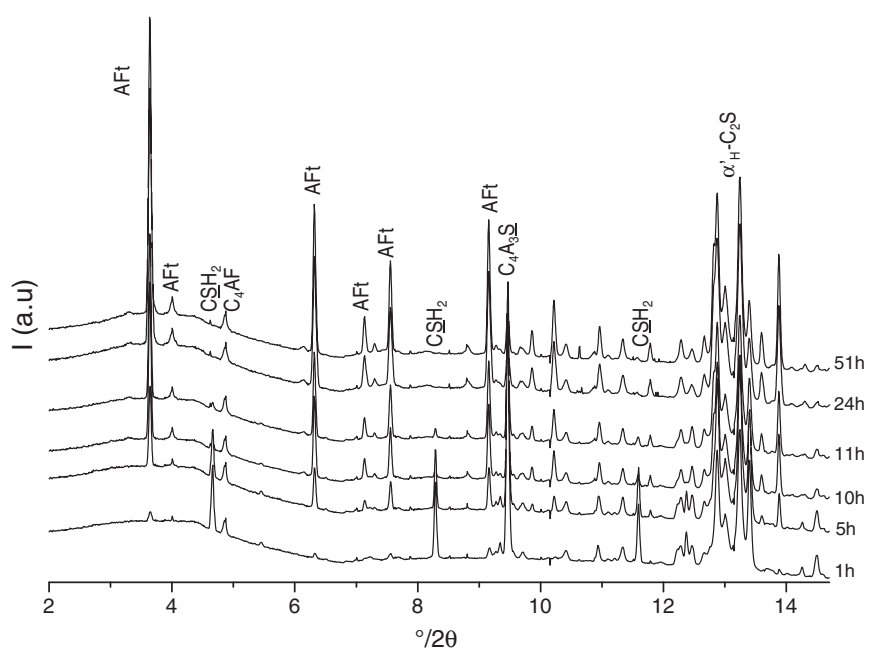

Fig. 3. Selected range of the SXRPD raw patterns for G10B2 recorded at different ages of hydration, with the main peaks due to a given phase labeled.
This measured behavior is in disagreement with the general accepted idea in the cement field: $\alpha$-belite is reported to have faster hydration kinetics than $\beta$-forms $[42,43]$. Furthermore, it was proved that $\beta$-form reacts more slowly than $\alpha$-forms in belite-rich cements [44]. It is worth highlighting that the hydration behavior of the remaining phases, excluding $\mathrm{C}_{2} \mathrm{~S}$, in belite rich cements, was almost identical. Thus, the amount of ions saturating pore solution was very similar in cements with different belite polymorphs. However, under our studied experimental conditions, $\beta-C_{2} S$ reacts faster than $\alpha_{H^{-}}^{\prime} C_{2} S$, to yield stratlingite, see reaction (2). This behavior may be justified due to the presence of high amounts of ettringite at early hours of hydration which implies a concomitant large quantity of amorphous aluminum hydroxide. The availability of amorphous $\mathrm{AH}_{3}$ promotes the precipitation of stratlingite, $\mathrm{C}_{2} \mathrm{ASH}_{8}$, from belite reaction (2). Thus, in G10B0 the reactivity of $\beta-\mathrm{C}_{2} \mathrm{~S}$ is hastened by this fact. Active belite-rich [45] and active BCSA [19,46] cements develop higher mechanical strengths (at any hydration age) when compared with non-active materials. Thus, the key issue seems to be the hydration products and not the polymorphism of the dicalcium silicate. According to a related study [46], BCSA pastes with higher percentages of stratlingite develop lower mechanical strengths. The precipitation of stratlingite requires an oversaturated pore solution in silicon and aluminum hydroxides [16], thus it is obvious that G10B2 paste will present less stratlingite as less ye'elimite is dissolved. Moreover, belite particle size was also studied by SEM. Fig. 4b and d shows SEM images of typical rounded belite particles in anhydrous B0 and B2 clinkers, respectively. The average belite particle size is again smaller in B0 clinker than in B2 sample.

Moreover, the enhanced reactivity of belite seems to be parallel to an enhanced reactivity of $\mathrm{C}_{4} \mathrm{AF}$. This phase is part of the interstitial phase of cements; hence it was not possible to establish a clear difference between particle sizes of $\mathrm{C}_{4} \mathrm{AF}$ present in both cements. However, due to the formation of AFm type phases in $\mathrm{G} 10 \mathrm{~B} 0$, when $\mathrm{C}_{4} \mathrm{AF}$ is actually dissolving, we can speculate that these may be iron-bearing AFm

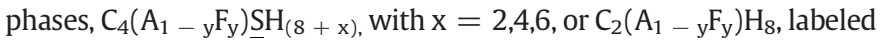
as AFm-10, AFm-12, AFm-14 and AFm* in the inset of Fig. 5a, respectively. Unfortunately, this hypothesis cannot be confirmed using the current data, and further studies are needed to clarify this issue.

The quantification of AFm type phases presents two additional problems: i) broad diffraction peaks due to both poor crystallinity and high disorder and ii) the lack of structural descriptions for some phases. Thus, the crystal structure reported for $\mathrm{C}_{4} \mathrm{ASH}_{12}$ [47] has been used to quantify all AFm phases by adjusting c-values (included in Table A2). AFm phases may present different hydration states according to $\mathrm{C}_{4} \mathrm{ASH}_{8}+\mathrm{x}$ with $\mathrm{x}=0,2,4,6$ and 8 [1]. In these experimental conditions, three AFm phases have been identified, AFm-10 ( $\mathrm{x}=2)$, AFm$12(\mathrm{x}=4)$ and AFm-14 $(\mathrm{x}=6)$, by measuring interlayer spacing according to [1], Table A2. Moreover, AFm* phase displayed a basal d-spacing close to $10.7 \AA$, which may correspond to $\mathrm{C}_{2} \mathrm{AH}_{8}$. The same strategy, detailed just above, was followed to quantify this phase.

G10B2 RQPA results were analyzed with the same methodology used for $\mathrm{G}_{-} \mathrm{C}_{4} \mathrm{~A}_{3} \mathrm{~S}$. The reaction degree of gypsum, ye'elimite and ettringite is given in Fig. 6a, while normalized direct RQPA results and the calorimetric curve are shown in Fig. 6b. These results are fully consistent with those obtained for $\mathrm{G}-\mathrm{C}_{4} \mathrm{~A}_{3} \mathrm{~S}$, i.e. AFt crystallization process is parallel to ye'elimite dissolution, and gypsum dissolution is faster. Moreover, the passivation effect observed in $\mathrm{G}-\mathrm{C}_{4} \mathrm{~A}_{3} \mathrm{~S}$ has also taken place in $\mathrm{G} 10 \mathrm{~B} 2$, achieving almost $\alpha=100 \%$ gypsum and $\alpha>80 \%$ ye'elimite and ettringite after one day of hydration, although at a lower extent. Finally, G10B2 presented an induction period close to $6 \mathrm{~h}$, when dissolution and crystallization of phases start to be significant.

The corresponding hydration study for G10B0 is shown in Fig. 6c and d. By comparing data of Fig. 6a and c, it can be observed that G10B0 sample does not present the induction period observed in G10B2. Moreover, the degrees of reaction after $1 \mathrm{~h}$ for all phases in G10B0 became almost equal to those determined at $6 \mathrm{~h}$ for G10B2. Gypsum was completely dissolved in G10B0 after 8 h of hydration, and almost 70\% of AFt was 

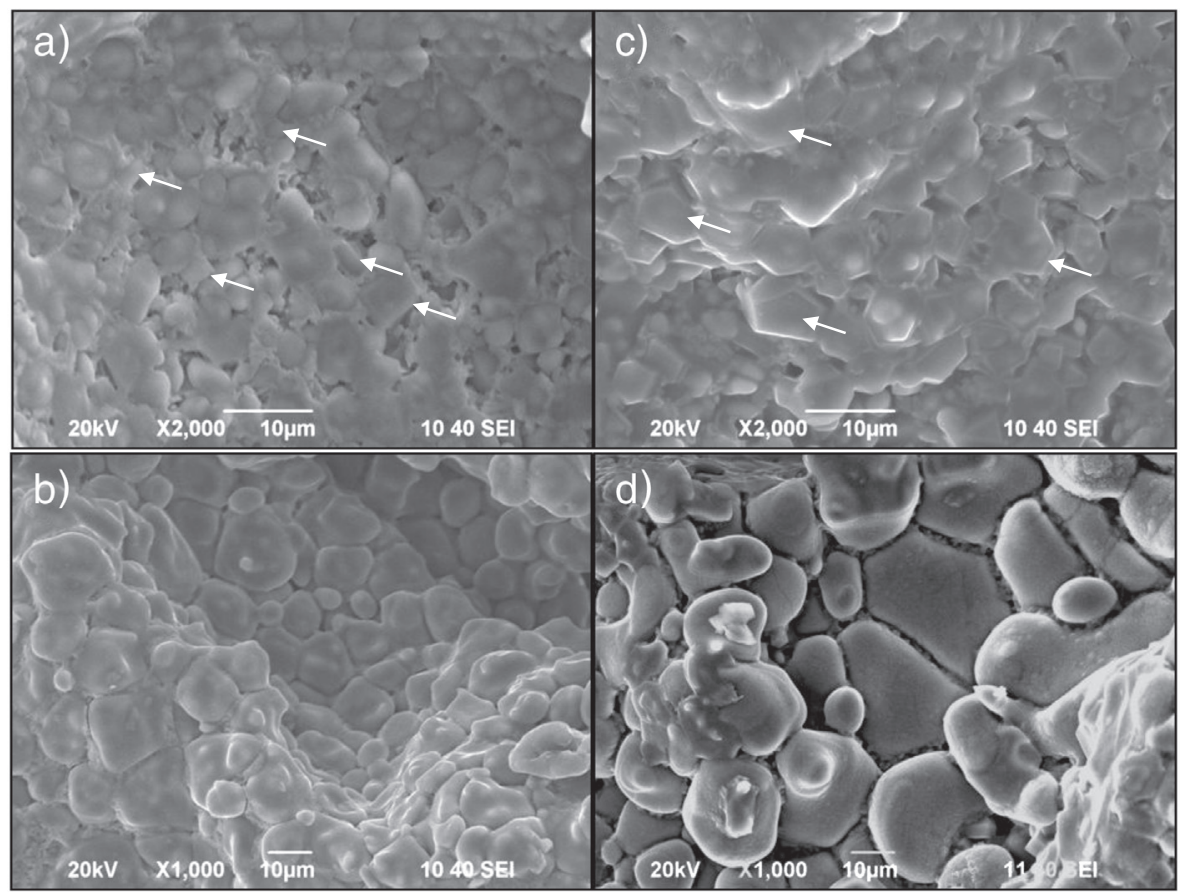

Fig. 4. SEM micrographs of (a) and (b) anhydrous non-active-BCSA clinker, and (c) and (d) anhydrous active-BCSA clinker

crystallized. These different kinetic behaviors justify the differences in the measured initial and final setting times. For G10B0, these values are 2.8 and 5.5 h, respectively; whereas for G10B2, the values are 3.5 and $5.8 \mathrm{~h}$, respectively. Finally, we highlight that for G10B0, after $12 \mathrm{~h}$ of hydration, $\beta-C_{2} S$ and $C_{4} A F$ start to react and the reported methodology to normalize the data cannot be longer applied. However, by

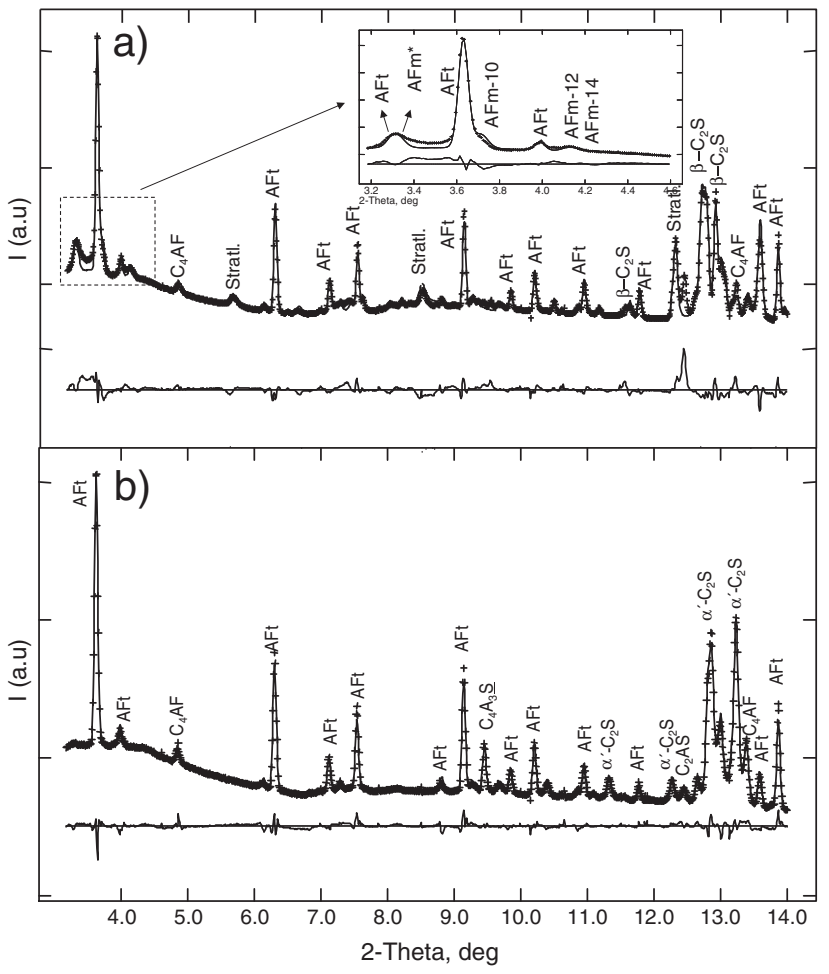

Fig. 5. Selected range of the Rietveld plot for (a) G10B0 at $26 \mathrm{~h}$ of hydration and (b) G10B2 at $24 \mathrm{~h}$ of hydration, with the main peaks due to a given phase labeled. Inset in (a): enlarged view of the lowest angle region. inspection of Table $\mathrm{A} 2$, it can be stated that passivation effect has not taken place in $\mathrm{G} 10 \mathrm{~B} 0$, as over $26 \mathrm{~h}$ of hydration $\mathrm{C}_{4} \mathrm{~A}_{3}$ S degree of reaction achieved $100 \%$. This is likely due to the higher reactivity of belite and ferrite phases.

The role of the type of calcium sulfate source, anhydrite and bassanite, as setting retarder was studied in A10B2 and B10B2 cements. Tables 1 and $\mathrm{A} 4$ give direct RQPA results as a function of hydration time for B10B2 and A10B2, respectively. A first inspection of these tables shows that there is only one chemical process occurring up to $24 \mathrm{~h}$, i.e. dissolution of sulfate sources and ettringite crystallization. Consequently, the degree of reaction was calculated, as detailed above, for A10B2 paste and the results are plotted in Fig. 7. It is well known that anhydrite kinetic dissolution is much slower than that of gypsum or bassanite [1], and it has been experimentally observed in this study. This observation further validates our experimental procedure and data analysis strategy. For A10B2 paste, the precipitation of ettringite is limited by CS dissolution, which starts to be significant up to $7 \mathrm{~h}$. Using these results we can also state that the predicted reactivity of ye'elimite with water to form AFm as main hydrated phase $[17,48]$ has not taken place within the first 6 h of hydration. Our results state that in spite of the fact that anhydrite is not dissolving until $6 \mathrm{~h}$, ye'elimite dissolution yields ettringite. This behavior disagreed with chemical reaction (4) but it is thermodynamic expected [49] and it has been also previously described $[50,51]$.

$\mathrm{C}_{4} \mathrm{~A}_{3} \underline{\mathrm{S}}+18 \mathrm{H} \rightarrow \mathrm{C}_{4} \mathrm{AS}^{\mathrm{S}} \mathrm{H}_{12}+2 \mathrm{AH}_{3}$

The slower kinetic of precipitation of AFt in A10B2 sample has allowed to follow the microstructure of this phase by inspecting FWHM of some diffraction peaks, for instance (010) diffraction peak at $\sim 9.7 \AA$. FWHM of this diffraction signal was 0.0494(3), 0.0439(6) and $0.0408(2)^{\circ}$ for 1,3 and $8 \mathrm{~h}$ of hydration, respectively. This sharpening of the diffraction peak is very likely due to the growth of the ettringite crystals.

B10B2 was analyzed at three selected times, 1, 12 and $24 \mathrm{~h}$, Table 1. Due to experimental requirements (sample loading in the capillaries, alignment and so on) it was not possible to measure the first $40 \mathrm{~min}$ of hydration. The dissolution of bassanite and precipitation of gypsum is reported to be a very fast process [52]. Our measurements fully 

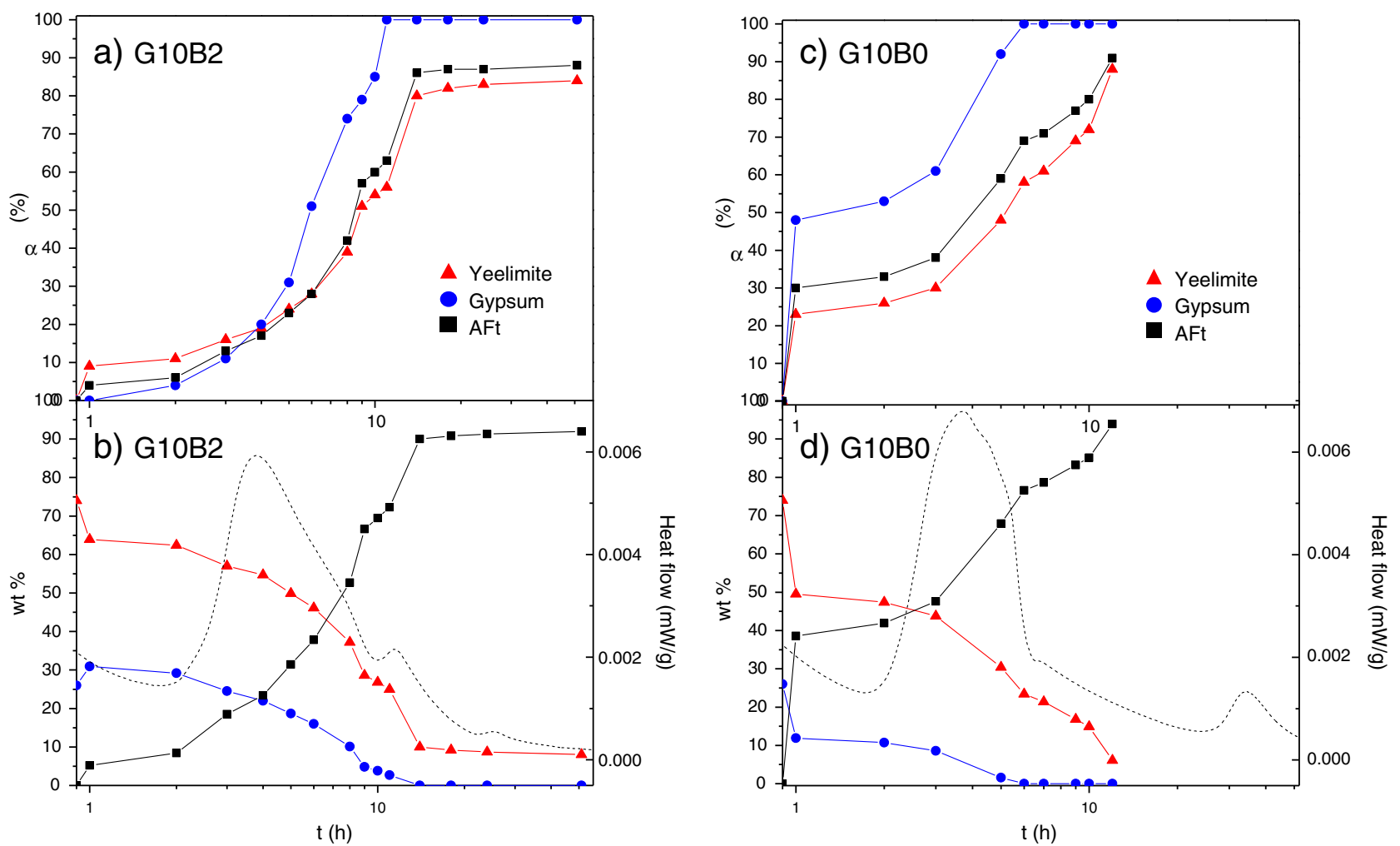

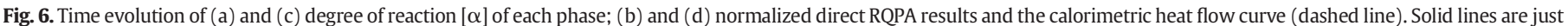
guide to the eyes.

agree with this behavior and after $1 \mathrm{~h}$ of hydration, bassanite was almost absent and gypsum had crystallized.

Furthermore, although ettringite is formed, 6 wt.\%, the measured amount of gypsum is very large, $\sim 11 \mathrm{wt} . \%$, because an amorphous fraction, aluminate hydrate, is also precipitating. In addition, we have inspected FWHM of (020) peak of gypsum in this sample after $1 \mathrm{~h}$ of hydration, being $0.0495(3)^{\circ}$; it was compared to the same peak of gypsum in G10B2 at the same time of hydration, $0.0457(4)^{\circ}$. These broader peaks are due, as expected, to smaller particle sizes for in-situ crystallized gypsum. Subsequent hydration reactions are similar to those already described for the gypsum-regulated cement, G10B2.

\section{Conclusions}

This work has allowed establishing kinetics and mechanisms for early age hydration of BCSA cements. The first important conclusion is the key influence of ye'elimite dissolution on further reactions. We have determined that non-active BCSA has a ye'elimite phase which dissolves at a higher pace than in active BCSA. For instance, after $1 \mathrm{~h}$

Table 1

Direct Rietveld quantitative phase analysis results (wt.\%) for B10B2 sample as a function of hydration time.

\begin{tabular}{llrrr}
\hline Phases & $\mathrm{t}_{0}$ & \multicolumn{1}{c}{$1 \mathrm{~h}$} & \multicolumn{1}{c}{$12 \mathrm{~h}$} & \multicolumn{1}{c}{$24 \mathrm{~h}$} \\
\hline$\alpha^{\prime} \mathrm{H}-\mathrm{C}_{2} \mathrm{~S}$ & $50.2(1.8)$ & $46.7(2)$ & $45.8(2)$ & $44.9(2)$ \\
$\mathrm{C}_{4} \mathrm{~A}_{3} \mathrm{~S}$ & $27.5(1.7)$ & $20.0(1)$ & $5.9(1)$ & $5.1(1)$ \\
$\mathrm{C}_{4} \mathrm{AF}$ & $8.9(6)$ & $11.4(2)$ & $10.7(2)$ & $10.2(2)$ \\
$\mathrm{C}_{2} \mathrm{AS}$ & $1.4(2)$ & $3.2(1)$ & $3.8(1)$ & $3.7(1)$ \\
$\mathrm{CT}$ & $1.9(2)$ & $1.9(1)$ & $1.6(1)$ & $1.6(1)$ \\
$\mathrm{CS} \mathrm{H}_{0.5}$ & $10.0(-)$ & $0.6(1)$ & $0.5(1)$ & $0.5(1)$ \\
$\mathrm{C} \overline{\mathrm{S}} \mathrm{H}_{2}$ & - & $11.3(2)$ & $0.8(1)$ & $0.6(1)$ \\
$\mathrm{A} \overline{\mathrm{Ft}}$ & - & $5.9(1)$ & $30.8(1)$ & $33.4(1)$ \\
\hline
\end{tabular}

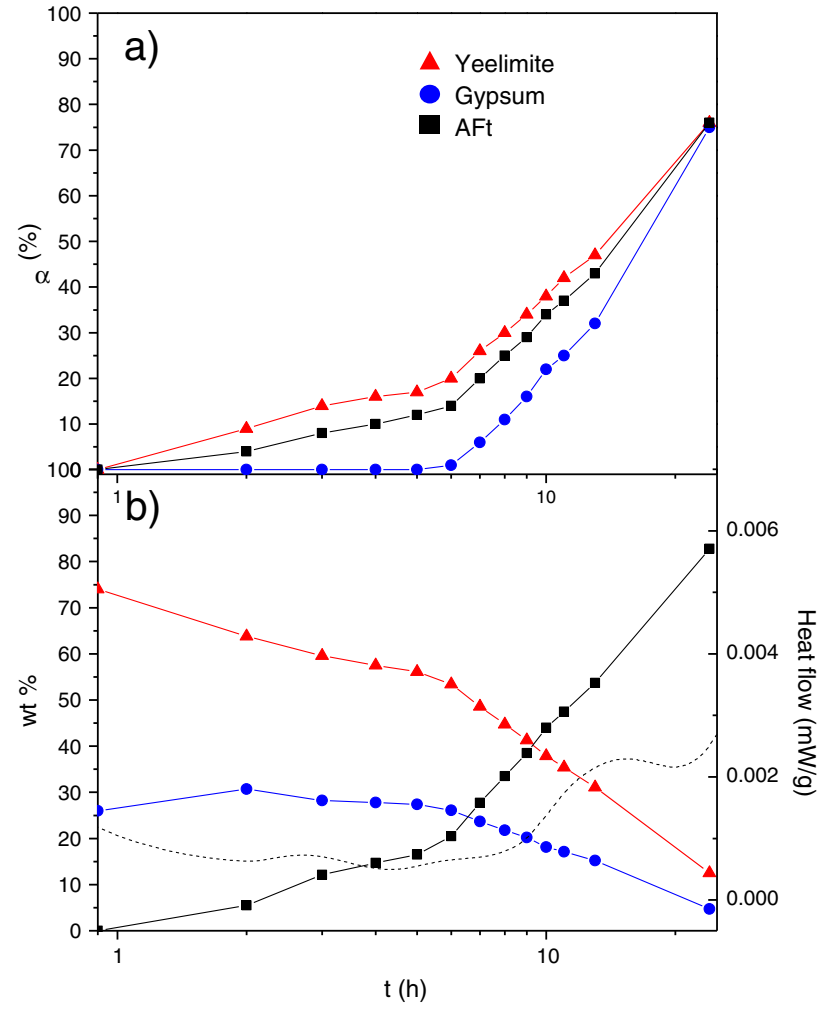

Fig. 7. Time evolution for A10B2 hydration of (a) degree of reaction $[\alpha]$ of each phase and (b) normalized direct Rietveld QPA results and the calorimetric heat flow curve (dashed line). Solid lines are just guide to the eyes. 
of hydration ye'elimite has dissolved $\sim 25 \%$ and $\sim 10 \%$ for non-active BCSA and active BCSA, respectively. The higher dissolution rate of ye'elimite and gypsum in non-active BCSA has likely provoked a higher $\mathrm{pH}$ value in the porous solution ( $\mathrm{pH}=12.4)$. Although, ettringite crystallization kinetic is slightly different, the degree of crystallization in both cements is similar, $\sim 85 \%$ over $\sim 12 \mathrm{~h}$. This behavior strongly influences $\mathrm{C}_{2} \mathrm{~S}$ hydration mechanism. The presence of high amounts of ettringite at early hours of hydration implies a concomitant large amount of available amorphous aluminum hydroxide, which can precipitate as stratlingite, $\mathrm{C}_{2} \mathrm{ASH}_{8}$, enhancing belite reactivity. In addition, if the formation of ettringite is somehow retarded, belite dissolution does not take place within the 50 first hours of hydration. Thus, it seems that the hydration behavior of belite is more dependent on the chemical environment (high or low available amorphous aluminum hydroxide content) than on its polymorphism. It must be highlighted that in our experimental hydration conditions, $\beta$-belite reacts faster than $\alpha^{\prime}{ }^{\prime}$-belite. Moreover, we have also observed that ettringite phase can be formed by the solely dissolution of ye'elimite in water, i.e. in the absence of dissolution of another sulfate-carrier source. Finally, the very fast dissolution of bassanite with precipitation of gypsum, as well as the low dissolution rate of anhydrite, has been quantified showing the accurateness of the reported methodology.

\section{Acknowledgments}

This work has been supported by Spanish MINECO through MAT2010-16213 research grant, which is co-funded by FEDER. I. Santacruz thanks a Ramón y Cajal fellowship, RYC-2008-03523. ALBA (Barcelona, Spain) is thanked for providing synchrotron beam time on BL04-MSPD beamline.

\section{Appendix A. Supplementary data}

Supplementary data to this article can be found online at http://dx. doi.org/10.1016/j.cemconres.2013.10.009.

\section{References}

[1] H.F.W. Taylor, Cement Chemistry, 2nd ed. Telford, UK, 1997.

[2] K.L. Scrivener, A. Nonat, Hydration of cementitious materials, present and future, Cem. Concr. Res. 41 (2011) 651-665.

[3] K.L. Scrivener, T. Füllmann, E. Gallucci, G. Walenta, E. Bermejo, Quantitative study of Portland cement hydration by X-ray diffraction/Rietveld analysis and independent methods, Cem. Concr. Res. 34 (2004) 1541-1547.

[4] M. Merlini, C. Meneghini, G. Artioli, T. Cerulli, Synchrotron radiation XRPD study on the early hydration of cements, Z. Cristallogr. 26 (2007) 411-416.

[5] M. Merlini, G. Artioli, C. Meneghini, T. Cerulli, A. Bravo, F. Cella, The early hydration and the set of Portland cements: in situ X-ray powder diffraction studies, Powder Diffract. 22 (2007) 201-208.

[6] J. Skibsted, C. Hall, Characterization of cement minerals, cements and their reaction products at the atomic and nano scale, Cem. Concr. Res. 38 (2008) 205-225.

[7] E.M. Gartner, D.E. Macphee, A physico-chemical basis for novel cementitious binders, Cem. Concr. Res. 41 (2011) 736-749.

[8] M.A.G. Aranda, A.G. De la Torre, Sulfoaluminate cement, in: F. Pacheco-Torgal, S. Jalali, J. Labrincha, V.M. John (Eds.), Eco-efficient Concrete, Woodhead Publishing, Cambridge, 2013, pp. 488-522.

[9] I. Janotka, U. Krajci, S.C. Mojumdar, Performance of sulphoaluminate-belite cement with high C4A3\$ content, Ceram. Silik. 51 (2007) 74-81.

[10] Q. Zhou, N.B. Milestone, M. Hayes, An alternative to Portland cement for waste encapsulation-the calcium sulfoaluminate cement system, J. Hazard. Mater. 136 (2006) 120-129.

[11] L. Zhang, F.P. Glasser, Hydration of calcium sulfoaluminate cement at less than $24 \mathrm{~h}$, Adv. Cem. Res. 14 (2002) 141-155.

[12] G.S. Li, E.M. Gartner, High-belite sulfoaluminate clinker: fabrication process and binder preparation, World Patent Application WO 2006/018569 A2.

[13] A.J.M. Cuberos, A.G. De la Torre, G. Álvarez-Pinazo, M.C. Martín-Sedeño, K. Schollbach, H. Pöllmann, M.A.G. Aranda, Active iron-rich belite sulfoaluminate cements: clinkering and hydration, Environ. Sci. Technol. 44 (2010) 6855-6862.

[14] M.C. Martín-Sedeño, A.J.M. Cuberos, A.G. De la Torre, G. Álvarez-Pinazo, L.M. Ordónez, M. Gateshki, M.A.G. Aranda, Aluminum-rich belite sulfoaluminate cements: clinkering and early age hydration, Cem. Concr. Res. 40 (2010) 359-369.

[15] S. Sahu, J. Havlica, V. Tomková, J. Majling, Hydration behaviour of sulphoaluminate belite cement in the presence of various calcium sulphates, Thermochim. Acta 175 (1991) 45-52.
[16] F. Winnefeld, B. Lothenbach, Hydration of calcium sulfoaluminate cements experimental findings and thermodynamic modelling, Cem. Concr. Res. 40 (2010) 1239-1247.

[17] F. Winnefeld, S. Barlag, Calorimetric and thermogravimetric study on the influence of calcium sulfate on the hydration of ye'elimite, J. Therm. Anal. Calorim. 101 (2010) 949-957.

[18] M. García-Maté, I. Santacruz, A.G. De la Torre, L. León-Reina, M.A.G. Aranda, Rheological and hydration characterization of calcium sulfoaluminate cement pastes, Cem. Concr. Compos. 34 (2012) 684-691.

[19] G.S. Li, G. Walenta, E.M. Gartner, Formation and hydration of low- $\mathrm{CO}_{2}$ cements based on belite, calcium sulfoaluminate and calcium aluminoferrite, Proceedings of the 12th ICCC, Montreal, Canada, 2007, p. TH3-15.3.

[20] F.P. Glasser, L. Zhang, High-performance cement matrices based on calcium sulphoaluminate-belite compositions, Cem. Concr. Res. 31 (2001) 1881-1886.

[21] V. Morin, G. Walenta, E. Gartner, P. Termkhajornkit, I. Baco, J.M. Casabonne, Proceedings of the 13th International Congress on the Chemistry of Cement, Madrid, Spain, 2011.

[22] V. Kasselouri, P. Tsakiridis, C. Malami, B. Georgali, C. Alexandriou, A study on the hydration products of a non-expansive sulfoaluminate cement, Cem. Concr. Res. 25 (1995) 1725-1736.

[23] R. Snellings, G. Mertens, R. Adriaens, J. Elsen, In situ synchrotron X-ray powder diffraction study of the early age hydration of cements blended with zeolite and quartzite fines and water-reducing agent, J. Appl. Clay Sci. 72 (2013) 124-131.

[24] A.N. Christensen, N.V.Y. Scarlet, I.C. Madsen, T.R. Jensen, J.C. Hanson, Real time study of cement and clinker phases hydration, Dalton Trans. 2003 (2003) 1529-1536.

[25] A.G. De la Torre, M.A.G. Aranda, Accuracy in Rietveld quantitative phase analysis of Portland cements, J. Appl. Crystallogr. 36 (2003) 1169-1176.

[26] L. León-Reina, A.G. De la Torre, J.M. Porras-Vázquez, M. Cruz, L.M. Ordonez, X. Alcobe, F. Gispert-Guirado, A. Larrañaga-Varga, M. Paul, T. Fuellmann, R. Schmidt, M.A.G. Aranda, Round robin on Rietveld quantitative phase analysis of Portland cements, J. Appl. Crystallogr. 42 (2009) 906-916.

[27] O. Pritula, L. Smrčok, J. Ivan, K. Iždinský, X-ray quantitative phase analysis of residuem of the reference Portland clinkers, Ceramics-Silikáty 48 (2004) 34-39.

[28] G. Álvarez-Pinazo, A. Cuesta, M. García-Maté, I Santacruz, E.R. Losilla, A.G. De la Torre, L. León-Reina, M.A.G. Aranda, Rietveld quantitative phase analysis of yeelimite-containing cements, Cem. Concr. Res. 42 (2012) 960-971.

[29] M.A.G. Aranda, A.G. De la Torre, L. León-Reina, Rietveld quantitative phase analysis of OPC clinkers, cements and hydration products, Rev. Mineral. Geochem. 74 (2012) 169-209

[30] S.R. Klaus, J. Neubauer, F. Goetz-Neunhoeffer, Hydration kinetics of $\mathrm{CA}_{2}$ and $\mathrm{CA}-$ investigations performed on a synthetic calcium aluminate cement, Cem. Concr. Res. 43 (2013) 62-69.

[31] D. Jansen, F. Goetz-Neunhoeffer, C. Stabler, J. Neubauer, A remastered external standard method applied to the quantification of early OPC hydration, Cem. Concr. Res. 41 (2011) 602-608.

[32] S.M. Clark, P. Barnes, A comparison of laboratory, synchrotron and neutron diffraction for the real time study of cement hydration, Cem. Concr. Res. 25 (1995) 639-646.

[33] A.C. Jupe, X. Turrillas, P. Barnes, S.L. Colston, C. Hall, D. Häusermann, M Hanfland, Fast in situ X-ray-diffraction studies of chemical reactions: a synchrotron view of the hydration of tricalcium aluminate, Phys. Rev. B 53 (1996) R14697-R14700.

[34] A. Cuesta, A.G. De la Torre, E.R. Losilla, V.K. Peterson, P. Rejmak, A. Ayuela, C. Frontera, M.A.G. Aranda, Structure, atomistic simulations, and phase transition of stoichiometric yeelimite, Chem. Mater. 25 (2013) 1680-1687.

[35] M. Knapp, I. Peral, L. Nikitina, M. Quispe, S. Ferrer, Technical concept of the materials science beamline at ALBA, Z. Kristallogr. Proc. 1 (2011) 137-142.

[36] A.C. Larson, R.B. Von Dreele, General Structure Analysis System (GSAS), Los Alamos National Laboratory Report LAUR, 2000, pp. 86-748.

[37] P. Thompson, D.E. Cox, J.B. Hasting, Rietveld refinement of Debye-Scherrer synchrotron X-ray data from Al203, J. Appl. Crystallogr. 20 (1987) 79-83.

[38] T. Roisnel, J. Rodríguez-Carvajal, WinPLOTR: a windows tool for powder diffraction pattern analysis, Mater. Sci. Forum 378-381 (2001) 118-123.

[39] D. Gastaldi, E. Boccaleri, F. Canonico, M. Bianchi, The use of Raman spectroscopy as a versatile characterization tool for calcium sulphoaluminate cements: a compositional and hydration study, J. Mater. Sci. 42 (2007) 8426-8432.

[40] H. Saalfeld, W. Depmeier, Silicon-free compounds with sodalite structure, Krist. Tech. 7 (1972) 229-233.

[41] R. Pérez-Bravo, G. Álvarez-Pinazo, J.M. Compana, I. Santacruz, E.R. Losilla, S. Bruque, A.G. De la Torre, Alite sulfoaluminate clinker: Rietveld mineralogical and SEM-EDX analysis, Adv. Cem. Res. (2012), http://dx.doi.org/10.1680/adcr.12.00044.

[42] I. Jelenic, A. Bezjak, M. Bujan, Hydration of $\mathrm{B}_{2} \mathrm{O}_{3}$-stabilized $\alpha^{\prime}$-and $\beta$-modifications of dicalcium silicate, Cem. Concr. Res. 8 (1978) 173-180.

[43] A.K. Chatterjee, High belite cements-present status and future technological options: part I, Cem. Concr. Res. 26 (1996) 1213-1225.

[44] A.J.M. Cuberos, A.G. De la Torre, M.C. Martín-Sedeño, L. Moreno-Real, M. Merlini, L.M. Ordónez, M.A.G. Aranda, Phase development in conventional and active belite cement pastes by Rietveld analysis and chemical constraints, Cem. Concr. Res. 39 (2009) 833-842.

[45] A. Gies, D. Knofel, Influence of alkalies on the composition of belite-rich cement clinkers and the technological properties of the resulting cements, Cem. Concr. Res. 16 (1986) 411-422.

[46] G. Álvarez-Pinazo, I. Santacruz, L. León-Reina, M.A.G. Aranda, A.G. De la Torre, Hydration reactions and mechanical strength developments of iron-rich sulfobelite 
eco-cements, Environ. Sci. Technol. (2013), http://dx.doi.org/10.1021/ie402484e (in press).

[47] R. Allmann, Refinement of the hybrid layer structure $\left[\mathrm{Ca}_{2} \mathrm{Al}(\mathrm{OH})_{6}\right]^{+} \cdot\left[1 / 2 \mathrm{SO}_{4} \cdot 3 \mathrm{H}_{2} \mathrm{O}\right]^{-}$, Neues Jahrb. Mineral. Monatsh. (1977) 136-144.

[48] J.T. Song, J.F. Young, Direct synthesis and hydration of calcium aluminosulfate $\left(\mathrm{Ca}_{4} \mathrm{Al}_{6} \mathrm{O}_{16} \mathrm{~S}\right)$, J. Am. Ceram. Soc. 85 (2002) 535-539.

[49] D. Damidot, F.P. Glasser, Thermodynamic investigation of the $\mathrm{CaO}-\mathrm{Al}_{2} \mathrm{O}_{3}-\mathrm{CaSO}_{4}-$ $\mathrm{H}_{2} \mathrm{O}$ system at $25{ }^{\circ} \mathrm{C}$ and the influence of $\mathrm{Na}_{2} \mathrm{O}$, Cem. Concr. Res. 23 (1993) 221-238.
[50] S. Berger, C.C.D. Coumes, P. Bescop, D. Damidot, Influence of a thermal cycle at early age on the hydration of calcium sulphoaluminate cements with variable gypsum contents, Cem. Concr. Res. 41 (2011) 149-160.

[51] M. Andac, F.P. Glasser, Pore solution composition of calcium sulphoaluminate cement, Adv. Cem. Res. 11 (1999) 23-26.

[52] C. Solberg, S. Hansen, Dissolution of $\mathrm{CaSO}_{4} \cdot 1 / 2 \mathrm{H}_{2} \mathrm{O}$ and precipitation of $\mathrm{CaSO}_{4} \cdot 2 \mathrm{H}_{2-}$ $\mathrm{O}$ : a kinetic study by synchrotron X-ray powder diffraction, Cem. Concr. Res. 31 (2001) 641-646. 